$4 \mathrm{Chu}$, S. and Downes, J.J. (2000) Odour-evoked autobiographical memories: Psychological investigations of Proustian phenomena. Chemical Senses 25, 111-116

5 Shobe, K.K. and Kihlstrom, J.F. (1997) Is traumatic memory special? Current Directions in Psychological Science 6, 70-74

6 Buffalo, S.H. and Squire, L.R. (2000) Memory distortions develop over time: Recollections of the O.J. Simpson trial verdict after 15 and 32 months. Psychological Science 11, 39-45

7 Thompson, C.P. et al. (1996) Autobiographical Memory: Remembering What and Remembering When, Erlbaum
8 Gonsalves, B. et al. (2004) Neural evidence that vivid imaging can lead to false remembering. Psychological Science 15, 655-660

9 Rubin, D.C. et al. (1998) Things learned in early adulthood are remembered best. Memory \& Cognition 26, 3-19

10 Welzer, H. and Markowitsch, H.J. (2005) Towards a bio-psycho-social model of autobiographical memory. Memory 13, 63-78

1364-6613/\$ - see front matter (c) 2005 Elsevier Ltd. All rights reserved. doi:10.1016/j.tics.2005.02.005

Letter

\title{
Neuroethics, reductionism and dualism
}

\section{Peter Jedlička}

\section{Institute of Physiology II, Goethe University, D-60590 Frankfurt, Germany}

In her article on ethical implications of neuroscience, Martha J. Farah suggests that growing knowledge about the neural substrate of mental processes might undermine our traditional (Cartesian?) understanding of personal identity [1]. Is neuroscience on the road to showing that character, consciousness and sense of spirituality are in fact no more than 'features of the machine'?

Importantly, the question of our individuality and free will is a metaphysical problem, a problem that goes beyond (meta) physics. If a neuroscientist says that we are nothing else but 'a pack of neurons', he ceases to talk as an empirical scientist and begins to talk as a philosopher (though sometimes not being aware of it). Strong reductionism is a metaphysical point of view identifiable by the typical slang that Julian Huxley called 'nothingelsebuttery'. There is a crucial difference between methodological (scientific) and ontological (metaphysical) reductionism. Reductionism is often a successful and therefore valuable scientific method [2], allowing us to explain complex processes in terms of more basic ones. However, if, even after successful reductive attempts, an unexplained residuum (for example 'qualia') remains, one should be careful to jump to the conclusion that mental events are nothing but neural states. From the fact that we can study psychic phenomena using empirical methods it does not follow that they are entirely reducible to lower ontological levels. (Conversely, success of empirical research shows clearly the inadequacy of 'spiritualistic' claims that the mind is wholly inexplicable by science.)

Of course, one can believe that some day science will come to a completely reductionistic and deterministic picture of the world. Nevertheless, such a conclusion is not empirically justified from present evidence. On the contrary, several logical, empirical and philosophical arguments have been put forward to support the idea that consciousness is an emergent and indeterministic phenomenon, possibly endowed with a 'downward causation' ability (e.g. [3-6]). Particularly worth noting is a recent proposal of Jeffrey Satinover [7], which interestingly combines novel findings in computational neuroscience, nonlinear dynamics and quantum physics. Satinover's hypothesis of a hierarchy of nested networks (reminiscent of Hofstadter's 'tangled hierarchy' [8]) challenges the conventional wisdom that quantum fluctuations are always self-averaging, and goes beyond Penrose's suggestions [6]. In fact, while rejecting strong reductionism, one need not accept the dualism of body and mind as two separate substances. The psychosomatic unity of human beings suggests the possibility of seeing us as both an inseparable and complementary union of mind and matter.

\section{Acknowledgements}

The author is on leave of absence from Institute of Pathological Physiology, SK-81108 Bratislava, Slovak Republic.

\section{References}

1 Farah, M.J. (2005) Neuroethics: the practical and the philosophical. Trends Cogn. Sci. 9, 34-40

2 Popper, K. (1974) Scientific reduction and the essential incompleteness of all science. In Studies in the Philosophy of Biology, pp. 259-284, University of California Press

3 Lindahl, B.I.B. (1997) Consciousness and biological evolution. J. Theor. Biol. 187, 613-629

4 Wallace, R. and Price, R. (1999) Neuromolecular computing: a new approach to human brain evolution. Biol. Cybern. 81, 189-197

5 Crutchfield, J.P. (1994) Is anything ever new? Considering emergence. In Santa Fe Institute Studies in the Sciences of Comlexity XIX (Cowan, G., Pines, D. and Melzner, D., eds), pp. 479-497, Addison Wesley

6 Penrose, R. (1994) Shadows of the Mind: A Search for the Missing Science of Consciousness, Oxford University Press

7 Satinover, J. (2001) Quantum Brain, John Wiley \& Sons

8 Hofstadter, D.R. (1979) Gödel, Escher, Bach: An Eternal Golden Braid, Basic Books

1364-6613/\$ - see front matter (c) 2005 Elsevier Ltd. All rights reserved. doi:10.1016/j.tics.2005.02.010 